\title{
The prospects for hydrogen as an energy carrier: an overview of hydrogen energy and hydrogen energy systems
}

\author{
Marc A. Rosen ${ }^{1}$ - Seama Koohi-Fayegh ${ }^{1}$ \\ ${ }^{1}$ Faculty of Engineering and Applied Science, University of Ontario Institute of Technology, 2000 Simcoe Street North, Oshawa, ON L1H 7K4, \\ Canada
}

Received: 24 November 2015/Revised: 5 January 2016/ Accepted: 6 January 2016/Published online: 14 February 2016

(C) Joint Center on Global Change and Earth System Science of the University of Maryland and Beijing Normal University and Springer-Verlag Berlin Heidelberg 2016

\begin{abstract}
Hydrogen is expected to play a key role as an energy carrier in future energy systems of the world. As fossil-fuel supplies become scarcer and environmental concerns increase, hydrogen is likely to become an increasingly important chemical energy carrier and eventually may become the principal chemical energy carrier. When most of the world's energy sources become nonfossil based, hydrogen and electricity are expected to be the two dominant energy carriers for the provision of end-use services. In such a "hydrogen economy," the two complementary energy carriers, hydrogen and electricity, are used to satisfy most of the requirements of energy consumers. A transition era will bridge the gap between today's fossil-fuel economy and a hydrogen economy, in which non-fossil-derived hydrogen will be used to extend the lifetime of the world's fossil fuels-by upgrading heavy oils, for instance-and the infrastructure needed to support a hydrogen economy is gradually developed. In this paper, the role of hydrogen as an energy carrier and hydrogen energy systems' technologies and their economics are described. Also, the social and political implications of hydrogen energy are examined, and the questions of when and where hydrogen is likely to become important are addressed. Examples are provided to illustrate key points.
\end{abstract}

Keywords Hydrogen energy - Production - Storage . Economics $\cdot$ Environment

Seama Koohi-Fayegh

sima.kouhi@uoit.ca

Marc A. Rosen

marc.rosen@uoit.ca

\section{Introduction}

The world has a wide variety of energy sources which can be harvested to produce an even wider variety of energy carriers. Some energy sources, such as fossil fuels, are also energy carriers. That is, their energy can be transported to and used by energy consumers in the same form as it is found. Other energy sources, such as falling water and solar radiation, must first be converted to an energy currency (commonly, electricity) before the energy can be used.

Presently, fossil fuels are the main energy sources and energy carriers in the world. However, the supply of fossil fuels is finite and their use causes environmental impacts. As supplies eventually begin to become scarcer and environmental concerns increase, the world will turn increasingly to alternative energy sources. But all foreseeable future energy sources (falling water, solar radiation, uranium, wind, tides, waves, etc.) cannot act as energy carriers for the provision of end-use services. Moreover, using present technology, these sources are capable of producing, for the most part, one energy carrier: electricity.

However, the world's societies cannot operate effectively with energy provided only in the form of electricity, as they also need chemical fuels and feedstocks. For example, many transportation vehicles, especially airplanes, cannot be economically flown using electricity (Scott 2007; Balat 2008). As use of fossil fuels declines and is replaced with energy supplies from non-fossil sources, the world could eventually become oversaturated with electricity and deficient in chemical fuels. 
Marchetti (1985) illustrated this point using historical energy-source data gathered by the Energy Systems Group of the International Institute for Applied Systems Analysis (IIASA) (see Fig. 1). The data are presented on a semilog plot with an abscissa of time and an ordinate of $F /(1-F)$, where $F$ is the fraction of total sources captured by the identified source. On the right-hand side of the ordinate, $F$ is presented on a nonlinear scale (the parameter $F /$ $(1-F)$ is used because it is important in the logistic substitution procedures which were used to model the data). Figure 1 shows that, as time progresses, an everdecreasing fraction of the world's energy sources has been supplied by wood, coal, oil and natural gas; the figure also predicts that an increasing fraction of energy sources in the future will be supplied by nuclear fission and "solfus" (solar and nuclear fusion). Wind energy can be treated as part of solfus. There likely exists a maximum fraction of energy transactions which can use electricity; assuming this value is 0.3 , it can be seen that the fraction of energy transactions using nuclear fission, solar and nuclear fusion will eventually surpass the 0.3 "ceiling," leading to an oversupply of electricity. In some regions and countries, surpluses of electricity have at times existed.

This argument, which follows from the future decline in fossil-fuel use shown in Fig. 1 and the limitations on energy end-uses serviceable with electricity, suggests that eventually it will be necessary to produce some chemical fuel, either directly from non-hydrocarbon energy sources or from the electricity they are already capable of producing. Other energy researchers (Muradov and Veziroglu 2008; Bose and Malbrunot 2007; Penner 2006; Smith and Santangelo 1980; Wallace and Ward 1983) have made similar arguments. Moreover, there is a consensus among many researchers that hydrogen is the most logical choice as a chemical fuel in the future societies of the world. An eventual "hydrogen economy," where hydrogen and electricity serve as complementary secondary energy carriers, has been envisioned for many decades (Muradov and
Veziroglu 2008; Dunn 2002; Marban and Valdes-Solis 2007; Elam et al. 2003; Bose and Malbrunot 2007; Sigfusson 2007; Penner 2006; Maack and Skulason 2005; Arnason and Sigfusson 2000; Lattin and Utgikar 2007; Midilli et al. 2005a, b; Scott 1987, 2007). Note that in a hydrogen economy there will remain other primary energy carriers such as uranium, which can be readily stored and transported, even if hydrogen and electricity become the main secondary energy carriers.

The objective of this paper is to provide an overview of hydrogen energy and hydrogen energy systems so as to describe the prospects for hydrogen as an energy carrier. In the paper, the use of hydrogen as an energy carrier is described, as are hydrogen energy systems and technologies, including methods used for the production, utilization, storage and distribution of hydrogen. Next, the economics of hydrogen energy systems and their social and political implications are discussed. Finally, the questions of when and where hydrogen energy will become important in the short and long terms are addressed, and advancements anticipated in hydrogen systems in the future are detailed. Throughout, aspects of hydrogen energy systems which are dependent on geographical location are pointed out.

\section{Background on energy and the environment}

\subsection{Energy}

Energy is a key driver of industrialized societies. Energy consumption is linked to living standards, lifestyles and population as well as its distribution between urban and rural areas. Population is growing in most countries (see Table 1), driving increased consumption of energy globally. Rising living standards are contributing to this trend, especially in developing economies. Concerns such as potential scarcities of many energy resources and the impact of energy systems on the environment also affect energy use.
Fig. 1 World primary energy substitution in terms of the fraction $F$ of total sources captured by the identified source [adapted from Marchetti (1985)]

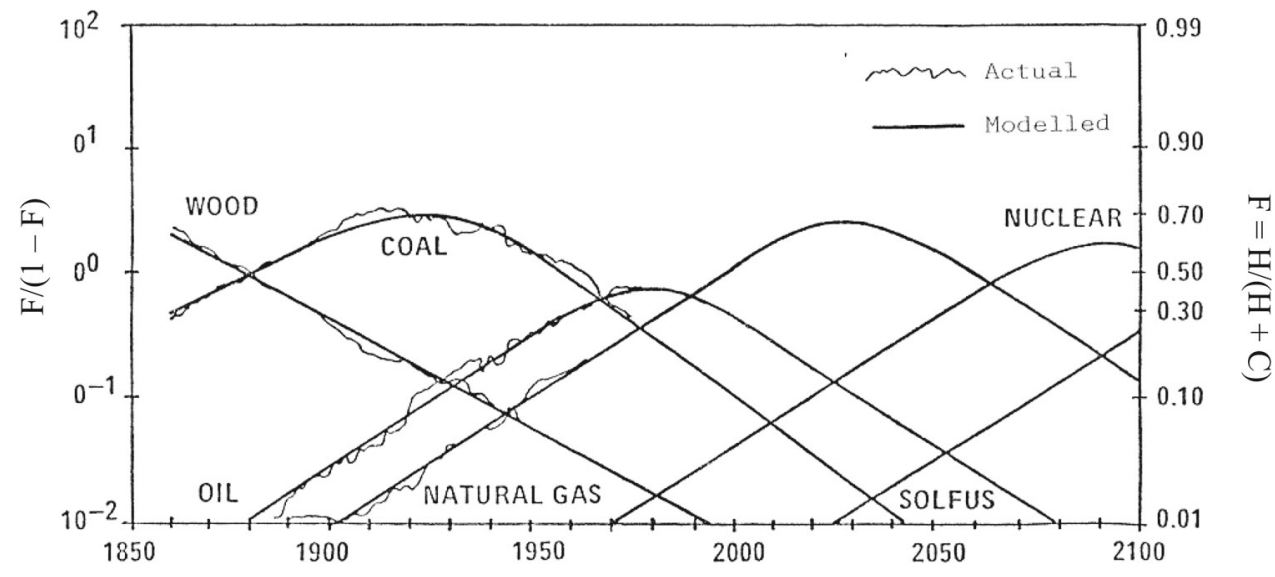


About $90 \%$ of the world's total primary energy use is currently met by fossil fuels. Alternatives to fossil fuels include hydro, nuclear, solar, wind, geothermal, wave and tidal energy (Hodge 2010; Veziroglu and Sahin 2008; Nersesian 2010; Ongena and Van Oost 2006; Lomonaco and Marotta 2014). Past global total primary energy use is given in Table 2 (top six rows), broken down by fuel type. Nuclear energy has been utilized mainly for electricity generation, but nuclear thermal energy can be used directly for such services as industrial heating, district heating and driving energy conversion processes (e.g., thermochemical hydrogen production).

Table 1 Global population (in millions), broken down by region and time [adapted from data at International Energy Agency (www.iea. org)]

\begin{tabular}{|c|c|c|c|}
\hline \multirow[t]{2}{*}{ Region } & \multicolumn{3}{|l|}{ Year } \\
\hline & 1990 & 2004 & 2030 \\
\hline China & 1120 & 1300 & 1450 \\
\hline India & 870 & 1100 & 1450 \\
\hline Remainder of developing Asia & 760 & 980 & 1300 \\
\hline Africa & 620 & 880 & 1450 \\
\hline Middle East & 180 & 200 & 320 \\
\hline Latin America & 360 & 430 & 600 \\
\hline Transition economies & 320 & 350 & 370 \\
\hline OECD $^{\mathrm{a}}$ countries & 1080 & 1190 & 1300 \\
\hline Overall & 5310 & 6430 & 8240 \\
\hline
\end{tabular}

${ }^{a}$ Organization for Economic Cooperation and Development
A mismatch sometimes exists between energy supply and demand. Fossil-fuel systems can be used effectively to meet demands when they occur. However, many renewable energy resources are available intermittently and nuclear plants operate best at a constant power level. Consequently, the capacity factor, defined as the ratio of actual to fullcapacity energy output over a period of time, varies notably for energy technologies.

Some feel that renewable energy resources can supply in the moderate term all anthropogenic energy requirements. Others feel that the potential is limited, e.g., the IEA (2004) estimated the "realisable" potential of renewable energy for electricity generation as approximately $108 \mathrm{EJ}$ annually, which is about one-quarter of the approximate $400 \mathrm{EJ}$ global energy use in 2000. Some of the challenges involved in increasing renewable energy use include:

- Renewable energy systems are often more costly than other energy options.

- Renewable energy resources are less concentrated or dense than fossil fuels and uranium, requiring large areas to be dedicated to harvesting the energy resource (Nel and Cooper 2009).

- Renewable energy resources are often available intermittently, often necessitating the use of energy storage. For example, the daily and seasonal variations in solar radiation lead to capacity factors for typical solar devices of approximately $18 \%$, while variations in wind yield capacity factors for common wind turbines of about $35 \%$ (Forsberg 2005).
Table 2 Breakdowns of past and predicted future global energy use and energy-related carbon dioxide emissions [data from International Energy Agency (www.iea.org)]

\begin{tabular}{|c|c|c|c|c|c|c|}
\hline \multirow[t]{2}{*}{ Annual quantity } & \multicolumn{6}{|l|}{ Year } \\
\hline & 1980 & 1990 & 2000 & 2010 & 2020 & 2030 \\
\hline \multicolumn{7}{|l|}{ Primary energy use rate (Gtoe/year) ${ }^{\mathrm{a}}$} \\
\hline Coal/peat & 1.6 & 2.0 & 2.0 & 2.6 & & \\
\hline Oil & 3.0 & 3.1 & 3.5 & 3.9 & & \\
\hline Natural gas & 1.4 & 1.8 & 2.0 & 3.3 & & \\
\hline Nuclear & 0.1 & 0.2 & 0.5 & 1.3 & & \\
\hline Hydro & 0.03 & 0.04 & 0.06 & 0.06 & & \\
\hline Combustible renewables and waste & 0.7 & 1.0 & 1.1 & 1.2 & & \\
\hline \multicolumn{7}{|l|}{$\mathrm{CO}_{2}$ emission rate $(\mathrm{Gt} /$ year $)$} \\
\hline \multicolumn{7}{|l|}{ By socioeconomic category } \\
\hline OECD countries & 10.9 & 11.0 & 11.8 & 12.6 & 13.5 & 14.4 \\
\hline Developing countries & 3.5 & 5.0 & 7.3 & 12.0 & 15.6 & 20.9 \\
\hline Transitioning economies & 3.6 & 3.5 & 2.4 & 2.6 & 2.7 & 2.8 \\
\hline \multicolumn{7}{|l|}{ By fuel source } \\
\hline Coal/peat & 5.7 & 7.2 & 6.5 & 10.7 & & \\
\hline Oil & 7.8 & 8.1 & 10.0 & 11.1 & & \\
\hline Natural gas & 3.5 & 4.2 & 5.0 & 5.4 & & \\
\hline
\end{tabular}

a Other primary energy forms, including solar, wind and geothermal energy, are relatively minor and thus not shown 
Many advanced techniques for improving efficiency have evolved and been applied in recent decades, such as exergy analysis (Rosen et al. 2008; Dincer and Rosen 2012). The achievement of energy sustainability has also become increasingly sought recently and been investigated (Rosen 2009; Dell 2004).

\subsection{Environmental impact}

Energy systems cause environmental impacts, leading many countries and regions to undertake extensive environmental assessments prior to approving and implementing new energy systems or major modifications to existing ones. Environmental impacts include climate change, stratospheric ozone depletion, acid precipitation and smog, among others.

Climate change has been shown by many to be a significant risk to humanity and thus has become a concern to policy makers and the public. Activities that lead to climate change are shown in Fig. 2, where it is seen that emissions of greenhouse gases (GHGs) from anthropogenic activity are a prime driver and that the eventual impacts of GHGs on ecosystems and people may motivate activities to mitigate and/or adapt to climate change. Substantial quantities of carbon dioxide, the most significant greenhouse gas, result from the combustion of fossil fuels, which account for the great majority of energy use globally. This point is supported Table 2, which shows past and predicted future increases in global energy use and $\mathrm{CO}_{2}$ emissions. Characteristics of the sources of carbon dioxide help illustrate the causes of climate change. Past global emissions of $\mathrm{CO}_{2}$ are given in the last four rows of Table 2, broken down by fuel source. Past and predicted future energy-related $\mathrm{CO}_{2}$ emissions are shown in rows 9-12 of Table 2 for several socioeconomic categories: developing countries, transition economies and the OECD.

\section{Hydrogen as an energy carrier}

Hydrogen is a useful energy carrier. It can be stored and transported, and it can be used as a fuel or converted to electrical energy in such devices as fuel cells. Hydrogen can be benign environmentally since, depending on the energy source from which it is derived, it can be produced from water and it reverts back to water after oxidation.

There are many reasons why hydrogen is a logical and appropriate choice as a chemical fuel to replace today's fossil fuels. The principal reason is that hydrogen is a complementary energy carrier to electricity (Scott 2007).
Fig. 2 Actions that lead to climate change and may motivate actions to mitigate it. The cycle starts with anthropogenic activity, which leads to GHG emissions. The eventual impacts on ecosystems and people may motivate anthropogenic activities to mitigate and/or adapt to climate change

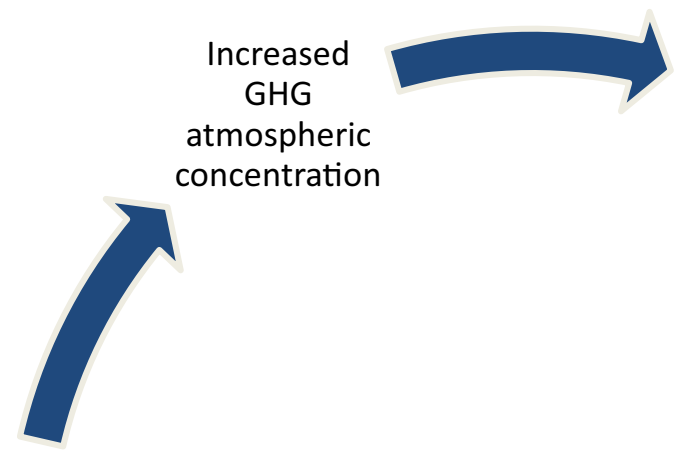

\section{Change in global temperature (with regional variations)}

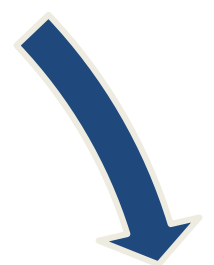

GHG emissions

Climate change

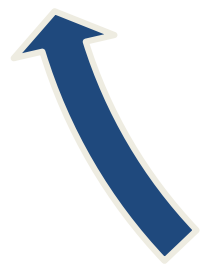

Anthropogenic activity

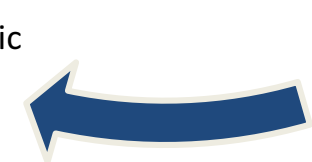

Impacts on ecosystems and people 
Both energy carriers are necessary as each can satisfy a range of energy service demands, some of which cannot be satisfied by the other. Hydrogen's advantages and disadvantages as a chemical fuel stem from its properties and characteristics. The principal advantages of hydrogen, as noted by several researchers (Johnson et al. 1981; Smith and Santangelo 1980; Wallace and Ward 1983; Scott 1987, 2007), are listed below:

- Producible. Hydrogen can be manufactured from hydrocarbon and, more significantly, non-hydrocarbon energy sources. Water, a widely available commodity, is the only other feed required.

- Utilizable. Hydrogen can be used as a chemical fuel and as a chemical feedstock in many industrial processes, such as the refining of metal ores and the upgrading of heavy oils and tars, as well as in transportation (Balat 2008; Turgut and Rosen 2010), and residential and commercial applications (Lubis et al. 2009).

- Storable. Hydrogen, unlike electricity, can be stored in large quantities in a variety of forms. The choice of what form hydrogen is best stored in for a given application depends on several factors, such as what the hydrogen will be used for.

- Transportable. There are many ways to transport hydrogen (e.g., road, rail, ship). Also, it is transportable over long distances using conventional pipeline technology with losses lower than those associated with electricity transport using high-voltage electrical lines. Thus, the energy from non-hydrocarbon energy sources located at great distances from energy consumers can be used to produce hydrogen and then easily transported.

- Environmentally benign. Hydrogen utilization involves oxidation, and the only direct major hydrogen oxidation product is water. A small quantity of nitrogen oxides is released when hydrogen is combusted in air, but these can be controlled with careful engine design (Wallace and Ward 1983). The environmental impacts with other phases in the life cycle of a hydrogen system are similar to those for other energy technologies and may be small or large, mainly depending on the source of hydrogen.

- Recyclable. Hydrogen is recyclable as an energy carrier, in that hydrogen oxidizes to water, which can be separated to generate hydrogen.

- Synergistic. Hydrogen energy systems usually incorporate many synergisms. That is, by using hydrogen as an energy carrier, other demands of the system can also be satisfied. For example, hydrogen production using electricity generated from CANDU (Canadian Deuterium Uranium) nuclear reactors can yield by-product heavy water using the combined electrolysis catalytic exchange (CECE) process (Vasyanina et al. 2008). The heavy water can, in turn, be supplied to the reactor, where it is required as a moderator and coolant.

Hydrogen also has some undesirable characteristics, some of which are listed below:

- Hydrogen storages have energy storage densities that are less than those for gasoline storages on both mass and volume bases. On a mass basis, the highest hydrogen energy storage density is attained using a liquid hydrogen storage, whose energy storage density is approximately $80 \%$ that of a gasoline storage. On a volume basis, the highest hydrogen energy storage density is attained using a type of metal hydride storage, whose energy density is approximately $35 \%$ that of a gasoline storage. In general, no hydrogen storage option has a high energy storage density on both a mass and volume basis. This is especially an issue in automotive applications of hydrogen as a fuel.

- It can leak from containment vessels due to its low density and small molecular size.

- Hydrogen can cause some materials problems. In the presence of hydrogen, for instance, some alloys tend to become embrittled (Cox and Williamson 1979).

- Hydrogen can be costly to produce for use as an energy carrier, especially compared to the cost of fossil fuels at present.

Through advanced engineering, most of hydrogen's undesirable characteristics can be dealt with.

One characteristic of hydrogen, which has been debated for many years (Hoffman 1981), involves how safely hydrogen can be used. The "Hindenburg Syndrome," which is characterized by a fear of anything in which hydrogen plays a role, was termed as a phrase after the Hindenburg dirigible accident in 1937 at Lakehurst, New Jersey. Hydrogen, like any fuel, does have dangerous properties (Cox and Williamson 1979), but the public's fears of hydrogen often appear to stem mainly from a fear of the unknown. Besides its dangerous properties, hydrogen also has some safe ones. The results of many studies of hydrogen's safety implications indicate that the dangers of hydrogen do not seem worse than those of gasoline, natural gas or any other fuel, but are merely different. Consideration of the flame temperature, explosion energy and flame emissivity of hydrogen suggests that it is safer than methane and gasoline. Due to its non-toxicity, a hydrogen leak does not cause environmental damage and hydrogen dissipates rapidly as it rises from its source due to its low density, reducing the risk of fire or explosion (Cipriani et al. 2014; Sharma and Ghoshal 2015). Furthermore, many groups, such as the US National Aeronautics and Space Administration (NASA) and the petrochemical industry, 
have been using hydrogen safely for many years (Scott 1987, 2007; Johnson et al. 1981). In general, most people working with or studying hydrogen have concluded that hydrogen can be used safely.

The preceding discussions suggest hydrogen may have a prominent role as an energy carrier in the future. The path from the present to the future can be broken down into three eras. The world is evolving from the present "fossilfuel era," an era in which fossil fuels and electricity are the main energy carriers and hydrogen is essentially not used as an energy carrier, to a "hydrogen era," an era in which there will be only two principal energy carriers: hydrogen and electricity. A "transition era" will link the fossil-fuel era to the hydrogen era.

The transition era will be characterized by a gradual substitution of chemical energy carriers. Light hydrocarbons, such as petroleum and natural gas, will gradually be replaced by heavy hydrocarbons, such as coal, oil shales and sands and tar sands. These, in turn, will likely be replaced by hydrogen. Scott (2007) notes that a key feature of such a transition era will be an integration of energy sources and energy carriers. Whereas in the fossil-fuel era, one energy source is often used to produce one energy carrier (e.g., uranium to produce electricity, or natural gas to produce heat), in the transition era, a set of energy sources more often will be used to produce a set of energy carriers. For example, methanol, hydrogen, electricity and low-grade heat were produced from natural gas, uranium and water at a demonstration plant in Julich, Germany (Scott 1987; Johnson et al. 1981). This integration will mainly be directed toward delaying a point in time when fossil fuels cannot be economically recovered and reducing environmental impacts.

Another type of integration involves the use of hydrogen produced from non-hydrocarbon sources in refining processes. The amount of products from refinery processes is greatly increased if such hydrogen is added to the heavy hydrocarbons, instead of removing carbon. In Ontario, Canada, for example, proposals have been made to use electricity generated from nuclear power plants to produce hydrogen for use in upgrading heavy oils into a marketable blend of liquid fuels.

The hydrogen era will be reached after fossil fuels become too expensive to recover economically and/or environmental or other imperatives cause modifications of our energy systems. Hydrogen is produced through from renewable energy sources using low-cost environmentally clean processes (Ursua and Gandia 2012). Then, it will be used as an energy carrier in ways which take advantage of its unique properties, and the infrastructure necessary to support a hydrogen era will be established. Final use technologies, especially fuel cells, will be widely spread (Ball and Weeda 2015; Ursua and Gandia 2012; Veziroglu and Macario 2011). The duration of the hydrogen era is anticipated to be great. According to Scott (2007), once established, the hydrogen era will last as long as advanced civilization lasts.

\section{Hydrogen energy systems and technologies}

Hydrogen energy systems are comprised of technologies for the production, utilization, storage and distribution of hydrogen. These technologies are discussed in this section. More detailed treatments of hydrogen energy systems can be found elsewhere (Muradov and Veziroglu 2008; Marban and Valdes-Solis 2007; Bose and Malbrunot 2007; Sigfusson 2007; Penner 2006; Maack and Skulason 2005; Lattin and Utgikar 2007). Many areas of hydrogen technology require research and/or development effort.

\subsection{Hydrogen utilization}

In the present fossil-fuel era, hydrogen is not often used as an energy carrier since supplies of fossil fuels are still relatively plentiful. Rather, it is mainly produced to satisfy industrial non-energy requirements throughout the world, especially in developed countries.

Presently, hydrogen is primarily used in (Johnson et al. 1981; Baker 1980; Hammerli 1984; National Academies of Engineering 2004):

- refinery processes (hydrocracking of heavy residual oils to produce high-quality gasoline, hydrodesulfurization of sulfur-bearing petroleum streams, etc.);

- the production of petrochemicals (alpha alcohols, polyolefins, etc.); and

- the production of chemicals (ammonia, methanol, etc.).

Hydrogen is also used to a lesser extent in the production of such products as drugs and semiconductors. Table 3 presents a breakdown of current annual hydrogen use on a global basis, as a percentage of total hydrogen production.

The use of hydrogen has evolved over recent decades, but similar trends have been observed. This can be observed in Table 4, where a breakdown is provided of annual hydrogen use in the 1970s in Canada and the USA. The breakdowns in Tables 3 and 4 exhibit quantitative similarities, despite the fact that they are for significantly different time periods and geographic regions.

In the transition era, hydrogen will continue to be used as an industrial chemical feedstock and will be increasingly used directly as a chemical fuel, and as an intermediate in the production of alternative and conventional chemical fuels (Lattin and Utgikar 2007). Thus, hydrogen will find uses in the transportation, commercial and residential sectors as well as in the industrial sector. Use of energy 
Table 3 Breakdown of current annual hydrogen use on a global basis [data from National Academies of Engineering (2004)]

\begin{tabular}{ll}
\hline Use & Breakdown $(\%)$ \\
\hline Ammonia production & 60 \\
Oil refining & 23 \\
Methanol production & 9 \\
Other & 8 \\
\hline
\end{tabular}

Overall annual hydrogen use is approximately $50 \times 10^{9} \mathrm{~kg}$ $\left(570 \times 10^{9} \mathrm{~m}^{3}\right)$

Table 4 Breakdown of annual hydrogen use (\%) in Canada and the USA in the 1970s [Data from Baker (1980)]

\begin{tabular}{llc}
\hline Use & Canada $(1978)^{\mathrm{a}}$ & USA $(1975)^{\mathrm{b}}$ \\
\hline Ammonia production & 43 & 60 \\
Oil refining & 33 & 27 \\
Synfuel production & 12 & - \\
Methanol production & 9 & 10 \\
Other & 3 & 3
\end{tabular}

${ }^{a}$ Overall annual hydrogen use was approximately $1.1 \times 10^{9} \mathrm{~kg}$ $\left(12 \times 10^{9} \mathrm{~m}^{3}\right)$. Data source: Hammerli (1984)

${ }^{\mathrm{b}}$ Overall annual hydrogen use was approximately $5.4 \times 10^{9} \mathrm{~m}^{3}$ $\left(60 \times 10^{9} \mathrm{~m}^{3}\right)$

technologies fed by various sources that exchange energy through numerous carriers is optimized in a case study by Maroufmashat et al. (2015). Besides the uses listed for hydrogen in the fossil-fuel era, researchers expect hydrogen also to have the following uses:

- a fuel for producing electricity in fuel cells (Ball and Weeda 2015; Granovskii et al. 2006; Thomas 2009; Barclay 2006), which combine hydrogen and oxygen electrochemically to produce electricity and water;

- a supplement to natural gas, which can be added directly in natural gas distribution networks;

- a feedstock in the manufacturing of synthetic fuels, especially methane and ammonia;

- a fuel for urban motor vehicles, locomotives, marine vessels and aircraft, using fuel cells and/or combustion engine technology (Beghi 1983; Scott 2007; LapeñaRey et al. 2010); and

- a fuel for space heating, in appropriate circumstances (Smith and Santangelo 1980).

In the hydrogen era, hydrogen will be the prime chemical energy carrier used globally (Scott 2007). By this time, the infrastructure necessary for large-scale use of hydrogen will likely be in place, at least partially. The sector which will rely most heavily on hydrogen will likely be transportation (Johnson et al. 1981; Baker 1980). Such use requires a global research effort focusing on the development of physical and chemical methods to store hydrogen in condensed phases at high volumetric and gravimetric densities when using it as a vehicular fuel.

A great deal of effort is being devoted in many countries, including Canada, to developing the technologies that will be necessary to use hydrogen in the future (Johnson et al. 1981; Hydrogen Industry Council 1984).

\subsection{Hydrogen in automotive applications}

The transportation sector largely depends on the fossil fuels for its operation and is responsible for a large portion of greenhouse gas emissions. In a move toward lowering $\mathrm{CO}_{2}$ emissions, this sector as well may benefit from the use of hydrogen as a fuel for vehicles. Hydrogen storage is one of the main barriers in hydrogen automotive applications, where weight and volume should be kept as low as possible. Various options have been proposed in the automotive industry for replacing current fuels with hydrogen: fuel cell cars and hydrogen internal combustion engine vehicles.

Hydrogen fuel cell electric vehicles appear as a viable options for transportation in the future as they cause no pollution and their range is comparable to that of the traditional internal combustion engine vehicles $(400-500 \mathrm{~km}$ on a single refueling, given a 700-bar onboard hydrogen storage) (Ball and Weeda 2015; Alazemi and Andrews 2015). Their high efficiency at part-load operation makes them suitable options for passenger cars (Verhelst 2014). If the hydrogen used in these vehicles is produced from low-/ zero-carbon feedstocks or if the $\mathrm{CO}_{2}$ generated during their production is captured and stored, these vehicles offer an effective means for decarbonising the entire fuel supply chain. To satisfy the requirements of normal operation, reasonable behavior during transients (e.g., accelerations and braking) and a longer life for the stack, fuel cell cars are designed in a hybrid format using a battery pack or capacitor with a fuel cell (Cipriani et al. 2014). However, material supply could become a limiting factor of widespread adoption of fuel cell vehicles (Verhelst 2014).

Hydrogen can also be used in internal combustion engines that are designed similarly to traditional combustion engines. The mature industry and a vast production infrastructure available for internal combustion engines make hydrogen internal combustion engines economically attractive. Furthermore, unlike fuel cell vehicles, these vehicles do not rely on materials that may limit their largescale production (Verhelst 2014). Some features of these engines that vary from traditional gasoline engines are the electronics unit control to properly manage the pressure in the injection and the hydrogen combustor. These engines are not emission free and emit nitrogen mixtures (Cipriani et al. 2014). 
If hydrogen vehicles are to be used in large numbers, they require an entirely new, dedicated hydrogen distribution and refueling infrastructure with sufficient geographic coverage for users. This includes a network of hydrogen refueling stations with capacities and densities that are compatible with hydrogen vehicles. This involves capital expenditures and high investment risk regarding the future uptake of hydrogen demand. Hydrogen can be produced at the station or elsewhere and delivered to the station and then stored for transfer to in-vehicle hydrogen units. The current state of deployment of hydrogen fueling stations in various locations in the world is reviewed by Alazemi and Andrews (2015).

It is estimated that petroleum-based fuels will retain their dominant role in the transport sector for the coming decades as they are relatively straightforward to handle, have a high volumetric energy densities, are easy to store onboard a vehicle and can use the existing distribution and refueling infrastructure (Ball and Weeda 2015). In the transition era when a large refueling station network is not yet deployed, hydrogen internal combustion vehicles with the ability to switch to traditional fuel when no hydrogen refueling station is available offer the users flexibility (Verhelst 2014).

\subsection{Hydrogen production}

Hydrogen production requires significant development effort at present because (a) some of the most difficult technological problems are associated with hydrogen production processes, and (b) storage, distribution and conversion technologies will not be used if economic methods to produce hydrogen are not first developed. Included in hydrogen production are processes for generating and purifying hydrogen, as well as processes for the liquefaction or compression of hydrogen, where applicable. As far as security of supply and greenhouse gas emissions are concerned, any advantage from using hydrogen depends on how the hydrogen is produced (Ball and Weeda 2015).

The main processes for hydrogen production include steam reforming of natural gas, catalytic decomposition of natural gas, partial oxidation of heavy oil, coal gasification, water electrolysis, thermochemical water decomposition, and photochemical, electrochemical and biological processes. The first four processes are based on fossil fuels.

The main energy sources for hydrogen production are shown in Fig. 3, where two main categories of energy source are shown: hydrocarbons and non-hydrocarbons (electricity and heat). For the hydrogen production processes using hydrocarbons such as fossil fuels and biomass, the hydrogen is derived from the hydrogen in the hydrocarbon itself and water. The hydrogen is derived from the hydrogen in water for the hydrogen production processes driven by electrical and thermal energy.

\subsection{Hydrogen production from hydrocarbons}

In the fossil-fuel era, hydrogen is produced almost exclusively from fossil fuels (Muradov and Veziroglu 2008; Santarelli et al. 2004; Turner et al. 2008; Yildiz and Kazimi 2006). The primary hydrogen production processes, which are being used presently or are expected to be used soon, are (Hammerli 1984; Smith and Santangelo 1980; Holladay et al. 2009; Rosen and Scott 1998; Turpeinen et al. 2008; Gnanapragasam et al. 2010; Forsberg 2007):

- catalytic steam reforming of light hydrocarbons, such as naphtha and, more commonly, natural gas;

- partial oxidation of heavy hydrocarbons, such as heavy oils and coal; and

- coal gasification (DOE 2008; Shoko et al. 2006).

- thermal cracking of methane, also called methane decarburation (Abanades et al. 2013; Kumar and Priyanshu 2015).

Most of the hydrogen produced worldwide today is from fossil fuels, primarily via steam reforming of natural gas. It is the less polluting option to obtain hydrogen from fossil fuels (Ball and Weeda 2015), and its efficiency ranges from 70 to $80 \%$ (Ursua and Gandia 2012). In this method, $\mathrm{CO}_{2}$ is produced as a by-product, although not more than burning the same amount of natural gas. Since $\mathrm{CO}_{2}$ emissions contribute to climate change, methods to manage their production such as $\mathrm{CO}_{2}$ sequestration are sometimes used. Methods such as high-temperature pyrolysis (decomposition in the absence of oxygen) of hydrocarbons are also available but are costly. Hydrogen production from water using non-fossil fuels can help avoid the environmental problems and limitations of fossil fuels. Nonetheless, hydrogen will likely continue to be produced from carbon compounds in the near future.

\subsection{Hydrogen production from non-hydrocarbons}

In the transition era, one of the reasons for producing hydrogen will be to lengthen the lives of fossil-fuel supplies. In line with this goal, it is expected that the production of hydrogen from non-hydrocarbon energy sources will begin (Muradov and Veziroglu 2008; Santarelli et al. 2004; Turner et al. 2008; Yildiz and Kazimi 2006). Several such processes which are expected to be important follow:

- water electrolysis using electricity from such energy sources as nuclear, solar, wind or hydraulic;

- thermochemical hydrogen production using high-temperature heat produced in concentrating solar energy devices or high-temperature nuclear reactors, and thermoelectrochemical cycles;

- photochemical and photoelectrochemical processes; and

- photobiological processes. 
Fig. 3 Main energy sources for hydrogen production. For the hydrogen production processes using hydrocarbons (top grouping), the hydrogen is derived from the hydrogen in the hydrocarbon itself and water. For the hydrogen production processes using electricity and heat (bottom two groupings), the hydrogen is derived from the hydrogen in water

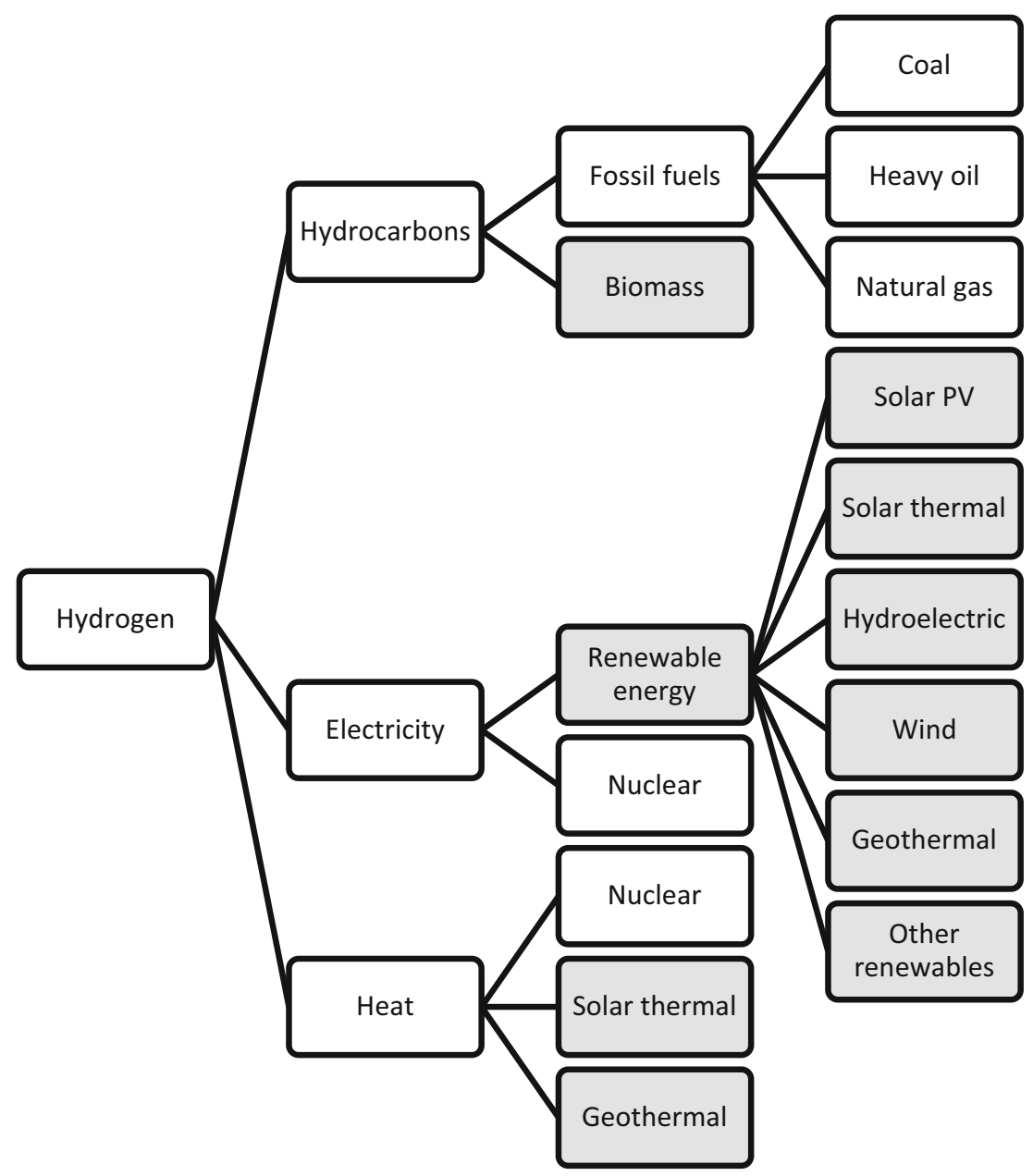

Relatively newer concepts such as chemical looping reforming for hydrogen production are being studied as well. In chemical looping reforming, the combustion process is split into three subprocesses by employing three separate reactors: an air reactor where the oxygen carrier is oxidized by air, a fuel reactor where natural gas is oxidized to produce a stream of $\mathrm{CO}_{2}$ and $\mathrm{H}_{2} \mathrm{O}$ and a steam reactor where the steam is reduced to produce hydrogen (Khan and Shamim 2014).

Water electrolysis is a process which produces hydrogen and oxygen by using electricity to split water. The main chemical reaction is as follows:

$2 \mathrm{H}_{2} \mathrm{O} \rightarrow 2 \mathrm{H}_{2}+\mathrm{O}_{2}$

Water electrolysis is used to produce hydrogen at present, although on a small scale (Johnson et al. 1981). In Canada, for instance, less than one percent of the total hydrogen generated is electrolytically produced. For instance, a large Cominco water electrolysis plant in British Columbia produced hydrogen at the rate of about 3.6 tonne/day (Silverstein 1982). Certain specialized processes require such hydrogen because of its high purity (over $99.5 \%$ compared with $97-98 \%$ for hydrocarbonderived hydrogen). Water electrolysis is a mature technology, but subject to inefficiencies due to the generation of electricity, e.g., in thermal power stations. High-temperature electrolysis, which utilizes water in the form of steam, is under development (Bhandari et al. 2014; Muradov and Veziroglu 2008; Turner et al. 2008; Yildiz and Kazimi 2006). In these systems, a major part of the energy required for electrolysis can be supplied in the form of high-temperature heat instead of electricity, which is more expensive. However, at their current research and development stage, these systems face issues such as electrolyte aging and electrode deactivation. The near-term non-fossil option for hydrogen production is likely to remain water electrolysis mainly due to its easy integration with renewable energy sources such as hydropower, wind and solar (Ursua and Gandia 2012; Bhandari et al. 2014). However, water electrolysis hydrogen production using renewable energies is currently limited to research and development projects.

Thermochemical water decomposition (or splitting), which is comprised of a sequence of chemical reactions for 
which the net reaction is water decomposition, is a significant future candidate for large-scale hydrogen production (Funk 2001; Rosen 2010; Lewis et al. 2009; Lewis and Masin 2009; Andress et al. 2009). The inefficiency of water electrolysis due to the conversion of heat to electricity in thermal power plants can be avoided through thermochemical cycles. Also, thermochemical water decomposition allows water to be decomposed at lower temperatures (around $850-1000^{\circ} \mathrm{C}$ ) than the temperature required for direct thermal decomposition of water to hydrogen and oxygen (over $2500{ }^{\circ} \mathrm{C}$ ). Some drawbacks of these systems include the corrosion and heat exchange problems caused by both high temperatures and the chemicals used, and the difficulty to find the heat sources for the processes. Many hydrogen production processes based on thermochemical water decomposition have been proposed, potentially driven by heat from nuclear power plants (Schultz et al. 2005; Naterer et al. 2009, 2010; Utgikar and Ward 2006; Forsberg et al. 2003; Forsberg 2003, 2007) and/or high-temperature solar thermal facilities (Kodama and Gokon 2007; Steinfeld 2005) or a combination of both in an integrated hydrogen production system (Orhan and Babu 2015). Two examples are the copper-chlorine cycle, which requires heat at temperatures as high as $550{ }^{\circ} \mathrm{C}$, and the sulfuroxygen-iodine process, which requires heat at about $1000{ }^{\circ} \mathrm{C}$

Photoelectrolysis is another developing technology that aims at obtaining hydrogen from the incidence of solar rays on semiconductors immersed in an aqueous solution that act as photocatalysts (Ursua and Gandia 2012). Photocatalytic processes are also being investigated as water-splitting paths to hydrogen production using solar energy (Preethi and Kanmani 2013). In these processes, the development of photocatalysts capable of harvesting a wide range of visible light in long-term operation to achieve high hydrogen production rates is highly desirable and is the focus of research (Srinivasan et al. 2015). Hybrid thermochemical cycles that utilize electricity as well as heat to decompose water are also under development (Forsberg 2007).

In the longer term, hydrogen may be produced from water using such heat-driven thermochemical processes. Such thermal processes for hydrogen production may prove less expensive than other options because heat is generally less expensive than electricity (Forsberg 2007). For instance, the cost of nuclear-based thermochemical hydrogen production has been estimated to be as low as $60 \%$ of that for nuclear-based hydrogen production by electrolysis (Forsberg et al. 2003). The specific thermochemical water decomposition processes that will ultimately prove to be the most economic are not yet known (Forsberg 2003).

Nuclear thermal energy is likely to prove an important energy source for hydrogen production, according to various authors (Bertel 2004; Marchetti 2006; Torjman and Shaaban 1998; Verfondern and Nishihara 2005; Forsberg 2005; Ponomarev-Stepnoi 2004; Onuki et al. 2005; Yildiz and Kazimi 2006; Lomonaco and Marotta 2014). In such instances, the nuclear reactor must supply heat at conditions that match those required by the hydrogen production process. Conventional nuclear technology can be used for hydrogen production processes requiring electricity. Various advanced nuclear technologies are possible for hydrogen production using thermochemical processes:

- The advanced gas reactor (AGR) is a commercial thermal reactor for electricity production that can attain coolant temperatures at the reactor exit of $650-750{ }^{\circ} \mathrm{C}$ during normal operation. The AGR core consists of a carbon dioxide coolant and uranium oxide fuel pellets in stainless-steel cladding within graphite blocks, which act as a moderator.

- The thermal energy for some thermochemical processes is the high-temperature gas-cooled reactor (HTGR), which has a maximum operating temperature of $800-1000{ }^{\circ} \mathrm{C}$ (Onuki et al. 2005).

- The modular helium reactor (MHR) is a thermal reactor that can be used for both hydrogen and electricity production. It uses a helium coolant, which can reach temperatures of $850-1000{ }^{\circ} \mathrm{C}$ at the reactor exit, and consists of a core of prismatic graphite blocks with ceramic fuel.

- The advanced high-temperature reactor (AHTR) is a new reactor design to provide high-temperature $\left(750-1000{ }^{\circ} \mathrm{C}\right)$ heat to enable efficient low-cost thermochemical production of hydrogen or electricity generation (Forsberg et al. 2003; Forsberg 2003). The AHTR uses a molten fluoride salt as a coolant and a solid coated-particle fuel in a graphite matrix.

Some state that hydrogen production through water electrolysis using renewably generated electricity from wind turbines and photovoltaic cells is not efficient as highquality energy carrier is converted to one of lower quality in these processes, and these energy sources should be used for meeting power demands. They suggest biologically based processes for hydrogen production such as use of gasification, fast pyrolysis and acid hydrolysis of harvested biomass with aqueous phase reforming (Tanksale et al. 2010). Artificial or biomimetic photosynthesis, where artificial photosynthetic systems capture light energy and drive proton reduction, is another biological path to hydrogen production (Magnuson et al. 2009). Some suggest microbial paths to hydrogen production such as dark fermentation, microbial electrolysis, biophotolysis and photofermentation (Hallenbeck 2011). However, all these processes suffer from technical barriers which prevent their practical applications at present. 
Many of these processes, such as thermochemical processes and high-temperature electrolysis, are only at the research and development stage. Hydrogen production processes using energy from renewable sources, such as photochemical, photoelectrochemical and photobiological processes, are only at the conceptual development or early research stage. Abbasi and Abbasi (2011) discuss and compare various processes for production of hydrogen from solar energy as well as other renewable sources such as wind, hydroelectric, geothermal, ocean thermal energy conversion, anaerobic digestion of biomass and biowastes and conclude that none of the technologies available for production of hydrogen from renewable sources are not economically viable at their current status.

In the hydrogen era, the production of hydrogen will be accomplished almost exclusively from water and non-hydrocarbon energy (Bargigli et al. 2004; Chiesa et al. 2005; Damen et al. 2006, 2007; Rydén and Lyngfelt 2006; Cohce et al. 2010), using the methods which will likely be introduced during the transition era.

\subsection{Hydrogen production via integrated processes}

Many of the methods to produce hydrogen described above can be integrated and operated simultaneously. This is usually done where each provides benefits and an integrated process seeks to exploit, on balance, the most advantageous aspects of each process.

\subsection{Overview of hydrogen production processes}

The main processes for hydrogen production are summarized in Fig. 4. Three main categories of processes are highlighted: processes based on fossil fuels, processes not based on fossil fuels, and integrated processes that advantageously combine one or more hydrogen production processes.

Apart from production of hydrogen using the various methods mentioned above, hydrogen can also be provided from the chemical industry where it is produced as a by-product. An example of such processes is the chlor-alkali process, where hydrogen is produced as a by-product in an electrochemical cell that produces chlorine and sodium hydroxide. Where available, such acido-alkaline electrochemical cells are recognized as cheap hydrogen production methods that can have a distinct role for sustainable energy conversion and storage and waste utilization (Zeradjanin et al. 2014).

\subsection{Hydrogen storage and distribution}

One of the principal reasons hydrogen complements well electricity as an energy carrier is that hydrogen can be stored over long periods of time. Furthermore, hydrogen production from intermittent renewable energy sources, such as solar energy sources, is only viable with an integration of a hydrogen storage system with production. The reversible storage of hydrogen is a substantial challenge, especially for use of hydrogen as a fuel in automotive applications. Hydrogen has a low energy density on a volume basis compared to the other fuels, requiring a much larger fuel tank for a vehicle operating on hydrogen rather than petrol/diesel. Furthermore, hydrogen is the lightest of all elements and harder to liquefy than methane and propane. Due to its low density and also its small molecular size, it can leak from containment vessels. In addition, for hydrogen to be used in automotive applications, the storage system should have the ability to extract/insert hydrogen at sufficiently rapid rates. To date, only relatively small-scale storages have been developed; however, several large-scale storages are being developed to satisfy future storage requirements, which are expected to be much greater than present ones. New materials with improved performance, or new approaches to the synthesis and/or processing of existing materials, are highly desirable for use of hydrogen as a vehicular fuel. Desirable characteristics for hydrogen storage materials are investigated by Yang et al. (2010) and Winter (2009), accounting for fuel cell vehicle requirements. Hydrogen can be stored in bulk in many forms and using many technologies:

- as a compressed gas in tube banks;

- as a cryogenic liquid (at $20.3 \mathrm{~K}$ ) in well-insulated tanks;

- as a mixed phase, called hydrogen slush;

- as a gas in underground reservoirs and caverns (as large quantities of natural gas are currently stored);

- in chemical bonds with other materials such as metal hydrides, which allow large quantities of gaseous hydrogen to be thermally adsorbed and desorbed in chemical bonds with the surface of certain metals;

- by weak adsorption of $\mathrm{H}_{2}$ molecules by a porous material such as glass microspheres, which allow large quantities of gaseous hydrogen to permeate into small (5-200 $\mu \mathrm{m}$ diameter) glass spheres; compared to metal hydrides, glass microspheres have twice the storage capacity per unit mass and one half the storage capacity per unit volume; and

- using cryoadsorbent technologies, which allow large quantities of gaseous hydrogen to be adsorbed and desorbed from the surfaces of the adsorbent materials when they are at low temperatures $(80 \mathrm{~K})$.

More detail on various hydrogen storage technologies is provided by Niaz et al. (2015). While some storage types, such as adsorptive storage, have already reached close to their potential storage limits, none of the hydrogen storage technologies mentioned above has yet reached a satisfactory level of performance (Eberle et al. 2009). All 
Fig. 4 Main processes for hydrogen production. Processes not based on fossil fuels are shown on the right (with gradient shading), while processes based on fossil fuels are shown on the left (with simple shading). Various integrated processes, represented by the non-shaded node in the center of the diagram, are possible by combining different hydrogen production processes

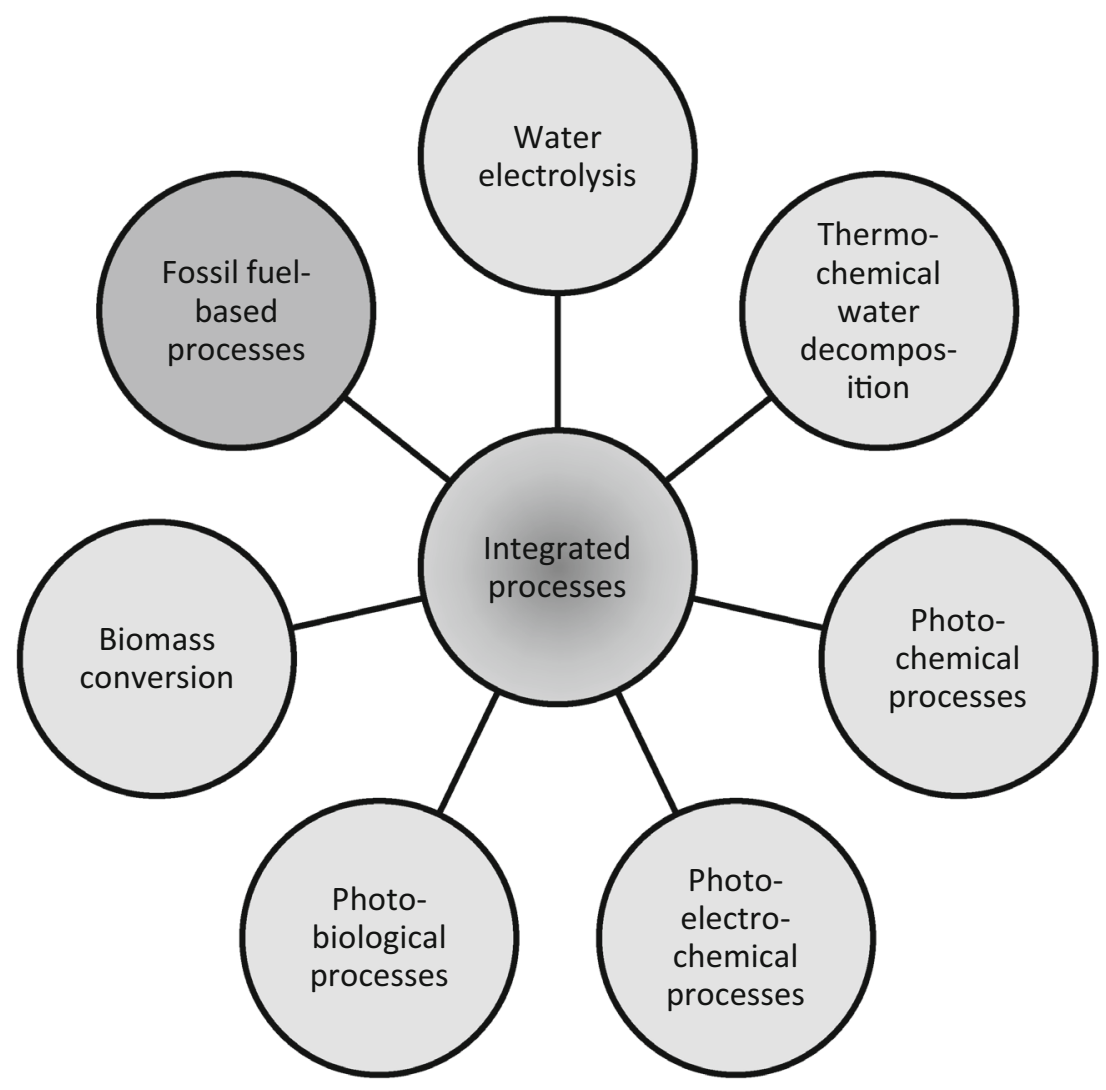

hydrogen storage technologies involving heat absorption or release face issues in thermal management, and their performance remains limited. Pressurized storage systems such as liquid hydrogen and compressed hydrogen gas as well as some adsorption storage systems have efficiency losses during compression and cooling; up to $20 \%$ of the energy content of hydrogen is required to compress the gas and up to $40 \%$ to liquefy it (Edwards et al. 2008; Dalebrook et al. 2013). In addition, there are numerous unresolved safety issues related to use of pressured hydrogen (Dalebrook et al. 2013). Eberle et al. (2009) review various hydrogen storage methods, including high-pressure and cryogenic liquid storage, adsorptive storage on high-surface-area adsorbents, chemical storage in metal hydrides and complex hydrides, and storage in boranes. They suggest liquid hydrogen and pressure storage to be the most viable solutions for large- and small-scale hydrogen storage at present, respectively. Chemical hydrogen storage systems appear to have much room for improvement as new materials are investigated (Eberle et al. 2009; Dalebrook et al. 2013). However, significant investments are required before these storage systems become economically viable for use in the industrial scale.

As well as technologies for hydrogen storage, several technologies for the distribution of hydrogen exist. Many of the hydrogen distribution methods use technologies also used for storage. For instance, the last three hydrogen storage technologies listed above are also hydrogen distribution technologies. Also, hydrogen can be transported in bulk by:

- pipeline as a gas, or possibly, for short distances, as a liquid;

- truck or rail as a highly compressed gas in tube tanks; and

- truck or rail or ship as a liquid.

In general, the choice of storage and distribution method depends on such factors as (a) what form the hydrogen is ultimately to be used in, (b) what constraints, such as volume or mass, exist, (c) which technologies are commercially available (metal hydrides, glass microspheres and cryoadsorbents are all at the research and development stage), and (d) which technologies are economically viable. Considering the cost of hydrogen for end users, in some cases, decentralized local hydrogen production using methane reforming or electrolysis of water becomes economically feasible.

\section{Economics of hydrogen energy systems}

An assessment of the economics of hydrogen energy systems must account for the costs of producing, storing, distributing and utilizing hydrogen (Ekins 2010; Kothari 
et al. 2008). In a hydrogen era, all of these costs are likely to be significant [in some cases even up to $95 \%$ (Ajanovic 2008)]. At present and in the near term, the cost of producing hydrogen is expected to remain a dominant factor in its use, which represents a pattern that has persisted over the last few decades (Johnson et al. 1981). Costs of hydrogen production are very dependent on the cost of primary energy source used for hydrogen production (e.g., photovoltaics).

Economic assessments of hydrogen production, storage, distribution and utilization technologies are dependent on many assumptions. For instance, the assumptions used in past assessments are available [e.g., the Ontario Hydrogen Task Force assumptions are listed by Johnson et al. (1981)], while the assumptions used in other economic assessments for hydrogen energy systems in Canada are published elsewhere (Hammerli 1984).

\subsection{Costs of hydrogen production}

It is not easy to project, in general, future costs for producing hydrogen from conventional and non-conventional methods. Many factors must be considered, such as changes in the costs of feedstocks, labor and capital. As these factors can vary markedly from country to country, a new analysis is required for each case considered.

The cost $C_{\mathrm{H}}$ of hydrogen energy can be expressed as the sum of the costs that contribute to its manufacture and distribution:

$C_{\mathrm{H}}=C_{\mathrm{P}}+C_{\mathrm{T}}+C_{\mathrm{S}}$

where $C_{\mathrm{P}}$ denotes the production cost, $C_{\mathrm{T}}$ the transportation cost and $C_{\mathrm{S}}$ the storage cost. The production cost can be further broken down as follows:

$C_{\mathrm{P}}=C_{\mathrm{E}}+C_{\mathrm{W}}+C_{\mathrm{F}}+C_{\mathrm{O}}+C_{\mathrm{M}}$

Here, $C_{\mathrm{E}}$ denotes the cost of energy needed to drive the process, $C_{\mathrm{W}}$ the cost of water, $C_{\mathrm{F}}$ the production facility cost, $C_{\mathrm{O}}$ operation costs and $C_{\mathrm{M}}$ maintenance costs.

Approximate present and predicted future unit costs of hydrogen are shown in Table 5. In that table, the low cost category is based on conventional technologies and energy sources such as steam reforming of natural gas and water

Table 5 Approximate range of present and predicted future unit $\operatorname{costs}^{\mathrm{a}}$ of hydrogen supply (National Academies of Engineering 2004)

\begin{tabular}{|c|c|c|c|c|}
\hline \multirow[t]{2}{*}{ Cost category } & \multicolumn{2}{|c|}{ Current } & \multicolumn{2}{|c|}{ Future } \\
\hline & $\$ / G J$ & $\$ / \mathrm{kg}$ & $\$ / G J$ & $\$ / \mathrm{kg}$ \\
\hline Low & 15 & 2.1 & 12 & 1.7 \\
\hline High & 66 & 9.1 & 30 & 4.2 \\
\hline
\end{tabular}

${ }^{a}$ Monetary values are in 2005 US\$ electrolysis using nuclear electricity, while the high cost category includes expensive renewable technologies such as solar photovoltaics. Also, current costs are based on present technology extended to the mid- to late 2000s, while future costs are based on current research and development efforts aimed at cost reductions being successful and therefore are not linked to a particular year.

Note that the cost of electricity greatly influences the costs of producing hydrogen from non-fossil sources, since the most advanced method of producing hydrogen is by electrolysis using electricity derived from non-fossil sources. Similarly, the cost of hydrogen production from fossil fuels is significantly dependent on their prices. More detailed comparisons of costs of hydrogen production via various technologies is provided in the literature (Parthasarathy and Narayanan 2014; Abanades et al. 2013), and a summary for selected technologies is shown in Table 6 . Costs of steam reforming of methane are strongly influenced by the natural gas price, and the authors often take into account this factor in estimating hydrogen production costs using this technology by considering linear dependences of hydrogen costs in relation to the natural gas prices.

It is instructive to consider how expectations of hydrogen costs have varied since discussions of a hydrogen era began to become prominent in the 1970s. To compare present costs with cost predictions made in the past, we concentrate on the province of Ontario in Canada. Ontario, with a population of about 13 million, has many hydrogen activities and initiatives ongoing. Evaluations of the economics of hydrogen in Ontario were carried out 30 years ago by the Ontario Hydrogen Energy Task Force (Johnson et al. 1981). Predicted costs of producing hydrogen are listed in Table 7 for the period between 1980 and 2025, based on data provided in the Task Force's report, for three hydrogen production methods: electrolysis using nuclearderived electricity, catalytic steam-methane reforming and the steam-iron coal gasification. In Table 7, low estimates and high estimates of costs are provided, with the ranges in unit costs intended to account for the primary uncertainties recognized at the time the estimates were made. A noteworthy observation is that the costs predicted in the past in Table 7 are relatively consistent with actual costs in Table 5.

An interesting feature of Table 7 is its projection that the cost of hydrogen produced from nuclear-derived electricity would be competitive with fossil-derived hydrogen between 1990 and 2000 in Ontario. In fact, it was expected that by 2000 the cost of hydrogen produced by electrolysis would be lower than the cost of hydrogen produced by either steam-methane reforming or coal gasification. This prediction was predicated mainly on the view that, during a transition era, the cost of electricity (derived from non- 
Table 6 Costs of hydrogen production technologies [data from Parthasarathy and Narayanan (2014)]

\begin{tabular}{llll}
\hline Cost category & Source & Technology & Hydrogen cost $(\$ / \mathrm{kg})$ \\
\hline Low & Methane & Steam reforming & 0.75 \\
& Coal & Gasification without $\mathrm{CO}_{2}$ sequestration & 0.92 \\
High & Nuclear & Electrolysis & $2.6-3.0$ \\
& & Water splitting & $1.4-2.3$ \\
& Biomass & Centralized biomass gasification & $1.2-2.4$ \\
& Solar & Photocatalytic water splitting & 5.0 \\
\hline
\end{tabular}

Table 7 Predicted plant gate unit costs (in $\$ / G J)^{\mathrm{a}}$ of hydrogen supply ${ }^{\mathrm{b}}$ based on estimates from 1981 [adapted from Johnson et al. (1981)]

\begin{tabular}{llllc}
\hline Process & 1980 & 1990 & 2000 & 2025 \\
\hline Water electrolysis via nuclear-derived electricity & 8.2 & $7.5-8.1$ & $5.6-6.6$ & $6.1-7.2$ \\
Steam reforming of natural gas & $4.9-5.4$ & $7.9-9.8$ & $10.7-11.8$ & $12.9-18.1$ \\
Steam-iron coal gasification & $9.1-9.8$ & $9.7-10.7$ & $10.3-11.5$ & $11.2-13.1$ \\
\hline
\end{tabular}

${ }^{a}$ Monetary values are in 1980 US\$. To obtain cost per unit mass instead of cost per unit energy, use the following conversion factor: $1 \$ /$ tonne $=138.1 \$ / \mathrm{GJ}$

b The hydrogen is assumed to be produced by a new plant and supplied at $7 \mathrm{MPa}$ fossil sources) would escalate at a slower rate than the cost of fossil fuels. In Ontario, this seems reasonable since the province has a successful and large nuclear power program and Canada has large uranium reserves. Other economic assessments (Mitchell 1983; Wallace and Ward 1983) also suggested that non-fossil-derived hydrogen would be competitive in Ontario before 2000. Although these predictions were not accurate in terms of timing, the expectation of higher costs for hydrogen from fossil fuels is likely to be valid at some time.

\subsection{Economics of hydrogen transport, storage and utilization}

The costs of bulk transport and storage of hydrogen are normally significantly less than production costs. For large volumes and large distances, transport of hydrogen as a compressed gas by pipeline is often the least expensive. However, this method requires large capital investment for infrastructure. Over short distances, small volumes of gaseous hydrogen can usually be transported most economically in tube tanks by truck (Ajanovic 2008). The transport cost of liquid hydrogen is much less than that for compressed gaseous hydrogen. However, the liquefaction process is very expensive, increasing the cost of hydrogen supply by approximately $60 \%$ (Muradov and Veziroglu 2008; Bose and Malbrunot 2007; Penner 2006; Ball and Weeda 2015). In lower hydrogen production capacity, onsite production is economically the best solution because the additional cost for hydrogen transport could be eliminated (Ajanovic 2008).

There are several uses for hydrogen which are expected to be economic in the near future. The earliest large-scale application of electrolytic hydrogen is expected to be in the upgrading of refinery products, where hydrogen produced by steam-methane reforming can be replaced. There may also be an opportunity for hydrogen to be used in biomassto-methanol conversion. A main thrust, however, has been and likely will continue to be to make the utilization of hydrogen as a transportation fuel economic.

\section{Social and political implications of hydrogen energy}

If the world's progress toward a hydrogen era is to proceed smoothly and rapidly, all issues surrounding the use of hydrogen energy must be addressed. As pointed out previously, hydrogen technologies must be developed to the stage where they are economically and commercially viable. This task includes overcoming any existing safety problems and building up the infrastructure, probably in a gradual manner, needed to support hydrogen energy systems. There are, however, many social and political issues surrounding hydrogen energy which must be understood (Ekins 2010; Kothari et al. 2008). Several of these issues are now discussed.

The numerous social and political implications of converting to a hydrogen era have been examined by governments, universities and private industries. In general, the entry of hydrogen is subject to the goals of a country, some of which are

- healthy levels of employment

- a reasonably good rate of economic growth

- reasonable stability in prices 
- viable balance of payments

- an equitable distribution of rising incomes.

In line with these goals, there are several factors that are instrumental in forming a hydrogen policy for a country. For example, important issues in the development and establishment of a national hydrogen energy policy for Canada have been examined over many years (Slotin 1983) and include the following:

- Canadian energy systems should be gradually directed away from hydrocarbons in the long term, which was a recommendation as long ago as 1981 of a Parliamentary Special Committee on Energy Alternatives (Lefebvre et al. 1981). In this way, Canada could (a) avoid the environmental problems accompanying continued, large-scale hydrocarbon use, (b) conserve its remaining hydrocarbons for non-energy uses, such as chemical production, and (c) reduce its use of foreign oil supplies.

- Canada possesses an array of hydrocarbon energy sources which includes large quantities of natural gas, coal, heavy oils and oil sands.

- Canada possesses an array of non-hydrocarbon energy sources which result in large quantities of hydro- and nuclear-generated electricity.

- Hydrogen technologies, some of which are being developed in Canada, can assist in accelerating the use of non-hydrocarbon resources while conserving hydrocarbon resources.

- In developing hydrogen technologies, Canada would not only help solve its own energy problems, but would also develop new Canadian high-technology industries.

Recognizing these issues, many studies over several decades have resulted in recommendations for increased funding of hydrogen projects. In Canada, for instance, such studies were carried out by the Special Committee on Alternative Energy and Oil Substitution (discussed earlier) and provincial authorities in Ontario and Quebec. Several encouraging developments in the hydrogen energy field followed in Canada including, for instance, the establishment of a Hydrogen Industry Council comprised of representatives from users and manufacturers, and an Institute for Hydrogen Systems in Ontario.

Public perceptions, often concerning costs and benefits, affect significant market and behavioral patterns for new technologies. Understanding public perceptions is therefore a crucial step in managing the transition to new technologies. Methodologies that can handle knowledge elicitation, representation and reasoning efficiently are needed to accomplish this task.

Public support and public opposition influence the implementation of hydrogen technologies. Therefore, public perception toward a hydrogen economy is often analyzed to help policy makers devise strategies that could assist in improving the public perception and implementing hydrogen technologies. This is often done by using surveys and mathematical tools such as Fuzzy Cognitive Mapping to analyze cognitive structures underlying beliefs related to a low-carbon future (Kontogianni et al. 2013). Financial gains, environmental concerns, safety and knowledge about the new technology seem to be some of the factors that are often analyzed in studying public perception toward any new technology, including renewable and hydrogen technologies. One study shows that willingness to pay to participate in projects contributing to the use of fuel cell vehicles despite the vehicle's current limitations (i.e., reduced range and limited refueling possibilities) seems to be driven mostly by users' expectation of personal financial gains (i.e., reduced running costs). In such cases, a financially attractive package is essential for hydrogen promotion among users (Kontogianni et al. 2013; Mourato et al. 2004). There seem to be not much safety concerns among some users about driving hydrogen-fueled vehicles. It seems that in highly regulated industries where rigorous tests are conducted to ensure safety, users may not be as concerned as expected about safety of hydrogen use (Mourato et al. 2004). In some studies, environmental considerations are found to affect users' willingness to pay for hydrogen technologies (Mourato et al. 2004). This could mean that improving public awareness of such technologies and air pollution promotes the use of these technologies in the future. In contrary, in some studies, users with better knowledge of the technology emphasize more the difficulties of the hydrogen future (Kontogianni et al. 2013).

Huijts et al. (2014) examine psychological determinants of citizens' supporting or opposing hydrogen fuel station technology. They suggest that policy makers should engage citizens in relatively effective, easy and appreciated supporting actions in order to receive support from users. They also show that users' opposing actions occur when they have a lower trust in industry. Gaining and keeping trust therefore seems important in minimizing oppositions against hydrogen technologies (Huijts et al. 2014).

\section{When and where will hydrogen come?}

The arguments leading to the conclusion that the world is inevitably moving toward a hydrogen era are often uncertain about one important detail: time. It is useful to know when hydrogen will start to play the role of an energy carrier, and when it will become a principal chemical energy carrier. Based on the discussions in this chapter of 
the technical, economic, social and political factors affecting hydrogen energy and the world's progress toward a hydrogen era, a question can be addressed, which was posed by Marchetti (1985): When will hydrogen come?

It is generally agreed that hydrogen energy will become important in different countries at different times. So, in answering the question of when hydrogen will come, one must also answer the question: Where will hydrogen come? Most of the predictions have been made for developed countries. This is because they will likely be the first countries to need hydrogen as an energy carrier (Sigfusson 2007; Penner 2006; Maack and Skulason 2005; Scott 2007; Johnson et al. 1981). This is not to say that developing countries will not need hydrogen. To the contrary, they will likely need hydrogen as much as any developed country if they hope to continue developing. However, the entry of developing countries into the transition era is almost certain to follow that of developed ones. Hence, most of the following discussion pertains to developed countries.

In trying to predict when and where hydrogen will come, many lines of reasoning, ranging from intuitive estimates to detailed calculations, have been used. In the early 1980s, many researchers predicted when they expect hydrogen to begin to become "important" as an energy carrier. This time would roughly correspond to the beginning of the transition era, following terminology used in this paper. In general, the values predicted for many different developed countries ranged from 1990 to 2020 .

Some of the most intriguing reasoning methods used to predict when hydrogen will important were presented by Marchetti (1973, 1985). In his 1973 paper, Marchetti introduced the concept of an "energy island," a small island on which massive amounts of nuclear energy would be generated. This energy would be distributed to the world's users in the form of hydrogen. Using what he called "dreamy guesses," Marchetti predicted that hydrogen energy will become important in 1991.

Subsequently, Marchetti (1985) developed two independent and more rigorous arguments which he used to predict when hydrogen would begin to penetrate the world's energy markets. In the first argument, he showed that, in the course of time, the market has required more fluid fuels, fuels that have ever-increasing hydrogen-tocarbon atomic ratios $(H / C)$. That is, wood $(H / C=0.1)$ was replaced by coal $(H / C=1)$, which was replaced by oil $(H /$ $C=2)$, which was finally replaced by natural gas $(H /$ $C=4$ ). This evolution is illustrated in Fig. 5, using the same plot format as in Fig. 1. In Fig. 5, Marchetti plotted $H / C$ in the world's fuel mix as a function of time in and, after modeling the data, predicted $H / C$ in the world's fuel mix would eventually be greater than four. But as no other hydrocarbons have a hydrogen-to-carbon ratio greater than 4, Marchetti deduced that $H / C>4$ in the world's fuel mix implies pure hydrogen must be used as a fuel. By extrapolating the curve on Fig. 5 to $H / C=4$, Marchetti predicted that pure hydrogen will begin to penetrate the world's market as a fuel around 2000.

In the second argument, Marchetti showed that, for many technologies, the time when a new technology is marketed (an "innovation") follows in quite an orderly way the time when the first successful prototype worked (an "invention"). Noting the existence of certain operating hydrogen-technology prototypes and applying this "relation" to them, Marchetti predicted hydrogen penetration of the market around 1995-2000.

Slightly later, Scott (1987) used the arguments of Marchetti and others to predict that between the years 1990 and 2015, all developed nations will reach a point when at least $0.5-2.0 \%$ of their energy transactions will involve non-hydrocarbon-derived hydrogen (using the terminology developed in this paper, this time would roughly correspond to the beginning of the transition era). By observing that in some developed countries, such as Germany, France and Japan, (a) nuclear-generated electricity is expected to saturate electricity markets, and (b) hydrogen energy systems' technologies are actively being developed, Scott predicted that the most developed countries will begin production of non-fossil hydrogen by 1990 . That is, they will enter the transition era by 1990 . Scott then predicted that between 2000 and 2010, most other developed countries will enter the transition era and that, by 2015, all developed countries will have entered the transition era. However, he notes that the countries entering after 2000 may be using technologies imported from the leading hydrogen-technology countries.

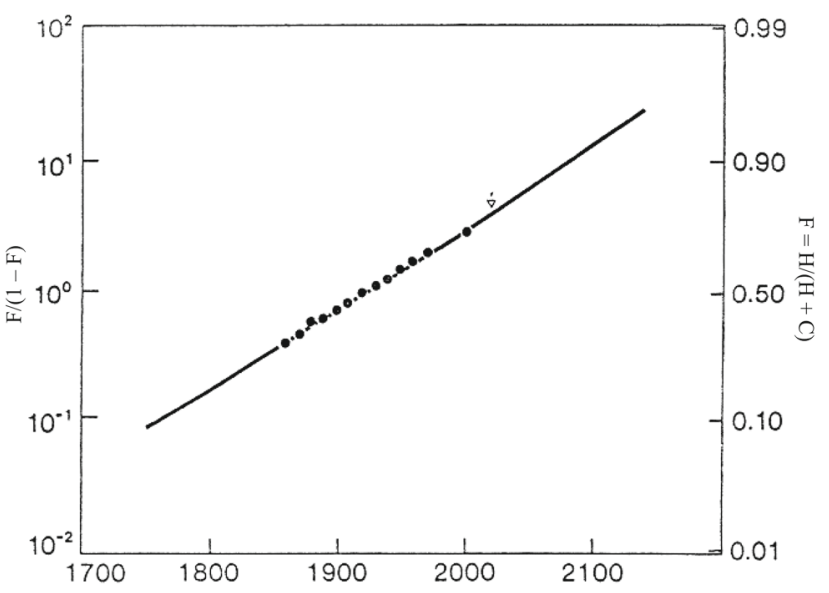

Fig. 5 Variation over time of the hydrogen-to-carbon atomic ratio $(H / C)$ in the world's fuel mix, in terms of the ratio $H /$ $(H+C)$ (adapted from Marchetti (1985)). The ratio $H / C$ is approximately 4 for natural gas, 2 for petroleum, 1 for coal and 0.1 for wood. The triangle denotes the point at which $H / C=4$ 
Other reports (e.g., Marchetti (1985)) predicted in the early 1980s that over the following few decades Canada, Japan and several members of the European Community (e.g., Germany, France and Belgium) would likely introduce hydrogen technologies in special applications. Scott (1987) examined Canada in detail and concluded that some regions in Canada will enter the transition era by 1990. Some characteristics of Canada that support this conclusion include the following:

- a unique energy matrix, including a large nuclear power generation capacity;

- a large and not fully developed hydraulic power generation capacity;

- advanced electrolyzer technologies; and

- some of the world's most extensive, but hard to extract, hydrocarbon resources.

Scott (1987) pointed out that of all regions of Canada, Ontario will probably be the first to enter the transition era, noting that Ontario's electricity markets had been saturated by nuclear-generated electricity since 1980 .

Some argue that these predictions have been proven valid and that some countries or regions have entered a transition era. Others feel that it is not clear if the transition era has been reached. Certainly, the fluctuations in energy prices and concerns about the environment over the last four decades have affected the predictions. But their general premises and conclusions appear to remain valid qualitatively, even if the predictions of dates have not been precise.

\section{Conclusions}

The world's supplies of fossil fuels, such as coal, oil and natural gas, are becoming scarcer, and concerns over the environmental impacts associated with their use are growing. Fossil fuels are gradually being replaced by nonfossil energy sources, such as solar, wind and nuclear energy. Whereas fossil energy sources are also energy carriers, non-fossil energy sources must be converted to energy carriers. Using present technology, non-fossil energy sources are converted almost exclusively to electricity. Although energy consumers need electricity to satisfy some of their energy demands, they also need a chemical fuel for certain applications, such as transportation. The logical choice for this chemical fuel is hydrogen because, among other reasons, it can be efficiently produced from non-fossil energy sources or from the electricity they currently can produce.

The technologies needed for hydrogen energy systems are currently receiving much research and development effort. There are many commercial processes for producing hydrogen from fossil sources, such as steam-methane reforming and partial oxidation of heavy oils. As well, there are several processes for producing hydrogen from non-fossil sources existing or under development, such as electrolysis and thermochemical water splitting. Technologies for the storage and distribution of hydrogen are also receiving much attention. Hydrogen can be stored and transported as a compressed gas or as a cryogenic liquid, or using methods by which hydrogen is absorbed onto the surface, or permeates into, specially chosen substances. Technologies for utilizing hydrogen in certain industrial processes, such as upgrading of heavy oils and production of methanol and ammonia, are presently in place; technologies for utilizing hydrogen as an energy carrier, mainly in transportation applications, are being developed.

Today, the cost of producing hydrogen is the most significant factor in the total cost of using hydrogen; the costs of utilization, storage and distribution are relatively small, except for liquefaction costs, which can increase the cost of supplied hydrogen by approximately $60 \%$. An economic assessment from several decades ago projected for Ontario that hydrogen produced from nuclear-generated electricity will be economically competitive with hydrogen produced by steam-methane reforming (the currently economic method) by 2000, while more recent assessments predict dates varying from 2020 to 2050. Thus, non-fossil-derived hydrogen may be used in the future in applications such as upgrading of refinery products, where it can replace hydrogen presently produced by steam-methane reforming.

Many countries will benefit from the introduction of hydrogen energy technologies, primarily because these technologies will help stabilize the fossil-fuel supply problems of many nations today. These problems are expected to worsen in the future. For the benefits to be realized, however, policies for the introduction of hydrogen technologies into the energy infrastructure of a country must be developed and politically supported. In Canada, political efforts have been spent in developing such policies, and many regions of Canada, especially Ontario, stand to benefit through the introduction of hydrogen technologies.

Most researchers agree that hydrogen technologies will be introduced in developed countries first. Although difficult to make, past estimates of when these countries will begin to use hydrogen as an energy carrier have ranged from 1990 to 2020. Countries such as Germany, France, Japan and Canada appear to be advanced the furthest down the path to hydrogen energy. These predictions, however, are subject to great uncertainty. Technological, economic, social and political factors will all continue to affect the prospects for hydrogen as an energy carrier. Nevertheless, it is likely that the world will eventually move toward an era when hydrogen and electricity are the world's two dominant energy carriers. 
Acknowledgments The authors gratefully acknowledge the financial support provided by the Natural Sciences and Engineering Research Council of Canada.

\section{References}

Abanades A, Rubbia C, Salmieri D (2013) Thermal cracking of methane into hydrogen for a $\mathrm{CO}_{2}$-free utilization of natural gas. Int J Hydrog Energy 38:8491-8496

Abbasi T, Abbasi SA (2011) 'Renewable' hydrogen: prospects and challenges. Renew Sustain Energy Rev 15(6):3034-3040

Ajanovic A (2008) On the economics of hydrogen from renewable energy sources as an alternative fuel in transport sector in Austria. Int J Hydrog Energy 33:4223-4234

Alazemi J, Andrews J (2015) Automotive hydrogen fuelling stations: an international review. Renew Sustain Energy Rev 48:483-499

Andress RJ, Huang X, Bequette BW, Martin LL (2009) A systematic methodology for the evaluation of alternative thermochemical cycles for hydrogen production. Int $\mathrm{J}$ Hydrog Energy 34:4146-4154

Arnason B, Sigfusson TI (2000) Iceland: a future hydrogen economy. Int J Hydrog Energy 25:389-394

Baker CR (1980) Production of hydrogen for the commercial market: current and future trends. In: Smith WN, Santangelo JG (eds) Chapter 12 in hydrogen production and marketing, ACS symposium series 116, Washington, D.C., pp 229-252

Balat M (2008) Potential importance of hydrogen as a future solution to environmental and transportation problems. Int $\mathrm{J}$ Hydrog Energy 33:4013-4029

Ball M, Weeda M (2015) The hydrogen economy: vision or reality? Int J Hydrog Energy 40:7903-7919

Barclay FJ (2006) Fuel cells, engines and hydrogen: an exergy approach. Wiley, Toronto

Bargigli S, Raugei M, Ulgiati S (2004) Comparison of thermodynamic and environmental indexes of natural gas, syngas and hydrogen production processes. Energy 29:2145-2159

Beghi G (1983) An introduction to hydrogen technology. In: Beghi G (ed) Hydrogen: energy vector of the future. Graham and Trotman, London

Bertel E (2004) Nuclear energy: the hydrogen economy. Nucl Energy Agency News 22:10-13

Bhandari R, Trudewind CA, Zapp P (2014) Life cycle assessment of hydrogen production via electrolysis: a review. J Clean Prod 85:151-163

Bose T, Malbrunot P (2007) Hydrogen: facing the energy challenges of the 21st century. John Libbey Eurotext, Paris

Chiesa P, Consonni S, Kreutz T, Williams R (2005) Co-production of hydrogen, electricity and $\mathrm{CO}_{2}$ from coal with commercially ready technology. Part A: performance and emissions. Int $\mathrm{J}$ Hydrog Energy 30:747-767

Cipriani G, Di Dio V, Genduso F, La Cascia D, Liga R, Miceli R, Galluzzo GR (2014) Perspective on hydrogen energy carrier and its automotive applications. Int J Hydrog Energy 39:8482-8494

Cohce MK, Dincer I, Rosen MA (2010) Thermodynamic analysis of hydrogen production from biomass gasification. Int $\mathrm{J}$ Hydrog Energy 3:4970-4980

Cox KE, Williamson KD Jr (eds) (1979) Hydrogen: its technology and implications. CRC Press, Boca Raton

Dalebrook AF, Gan W, Grasemann M, Moret S, Laurenczy G (2013) Hydrogen storage: beyond conventional methods. Chem Commun 49:8735-8751

Damen K, Troost M, Faaij A, Turkenberg W (2006) A comparison of electricity and hydrogen production systems with $\mathrm{CO}_{2}$ capture and storage. Part A: review and selection of promising conversion and capture technologies. Prog Energy Combust Sci 32:215-246

Damen K, Troost M, Faaij A, Turkenberg W (2007) A comparison of electricity and hydrogen production systems with $\mathrm{CO}_{2}$ capture and storage. Part B: chain analysis of promising CCS options. Prog Energy Combust Sci 33:580-609

Dell R (2004) Clean energy. Royal Society of Chemistry, London

Dincer I, Rosen MA (2012) Exergy: energy, environment and sustainable development, 2nd edn. Elsevier, Oxford

DOE (2008) Hydrogen from coal program: research, development and demonstration plan for the period 2008 through 2016. External report, US Department of Energy. http://fossil.energy. gov/programs/fuels/index.html

Dunn S (2002) Hydrogen futures: toward a sustainable energy system. Int J Hydrog Energy 27:235-264

Eberle U, Felderhoff M, Schüth F (2009) Chemical and physical solutions for hydrogen storage. Angew Chem Int Edit 48: $6608-6630$

Edwards PP, Kuznetsov VL, David WIF, Brandon NP (2008) Hydrogen and fuel cells: towards a sustainable energy future. Energy Policy 36:4356-4362

Ekins P (2010) Hydrogen energy: economic and social challenges. Earthscan, London

Elam CC, Padro CEG, Sandrock G, Luzzi A, Lindblad P, Hagen EF (2003) Realizing the hydrogen future: the International Energy Agency's efforts to advance hydrogen energy technologies. Int J Hydrog Energy 28:601-607

Forsberg CW (2003a) Hydrogen, nuclear energy and advanced hightemperature reactor. Int J Hydrog Energy 28:1073-1081

Forsberg CW (2003b) Hydrogen, nuclear energy, and the advanced high-temperature reactor. Int J Hydrog Energy 28:1073-1081

Forsberg C (2005) Futures for hydrogen produced using nuclear energy. Prog Nucl Energy 47:484-495

Forsberg CW (2007) Future hydrogen markets for large-scale hydrogen production systems. Int J Hydrog Energy 32:431-439

Forsberg CW, Peterson PF, Pickard PS (2003) Molten salt-cooled advanced high temperature reactor for production of hydrogen and electricity. Nucl Technol 144:289-302

Funk JE (2001) Thermochemical hydrogen production: past and present. Int J Hydrog Energy 26:185-190

Gnanapragasam NV, Reddy BV, Rosen MA (2010) Feasibility of an energy conversion system in Canada involving large-scale integrated hydrogen production using solid fuels. Int J Hydrog Energy 35:4788-4807

Granovskii M, Dincer I, Rosen MA (2006) Life cycle assessment of hydrogen fuel cell and gasoline vehicles. Int J Hydrog Energy 31:337-352

Hallenbeck PC (2011) Microbial paths to renewable hydrogen production. Adv Biochem Eng Biot 2(3):285-302

Hammerli M (1984) When will electrolytic hydrogen become competitive? Int J Hydrog Energy 9:25-52

Hodge BK (2010) Alternative energy systems and applications. Wiley, Hoboken

Hoffman P (1981) The forever fuel: the story of hydrogen. Westview Press, Boulder

Holladay JD, Hu J, King DL, Wang Y (2009) An overview of hydrogen production technologies. Catal Today 139:244-260

Huijts NMA, Molin EJE, Wee BV (2014) Hydrogen fuel station acceptance: a structural equation model based on the technology acceptance framework. J Environ Psychol 38:153-166

Hydrogen Industry Council (1984) New industrial opportunities with hydrogen technologies. Int J Hydrog Energy 9:9-23

IEA (2004) World energy outlook 2004. International Energy Agency, Paris

Johnson AC, Barnstaple AG, Bates JG, Boardman BR, Dewees DN, Fleck FC, Taylor JB, Schofield LJ, Soots V, Wank H (1981) 
Hydrogen, a challenging opportunity. Report of the Ontario hydrogen energy task force. Ontario Government Publications Services, Toronto

Khan MN, Shamim T (2014) Investigation of hydrogen production using chemical looping reforming. Energy Procedia 61: 2034-2037

Kodama T, Gokon N (2007) Thermochemical cycles for hightemperature solar hydrogen production. Chem Rev 107: 4048-4077

Kontogianni A, Tourkolias C, Papageorgiou EI (2013) Revealing market adaptation to a low carbon transport economy: tales of hydrogen futures as perceived by fuzzy cognitive mapping. Int $\mathrm{J}$ Hydrog Energy 38:709-722

Kothari R, Buddhiand D, Sawhney RL (2008) Comparison of environmental and economic aspects of various hydrogen production methods. Renew Sustain Energy Rev 12:553-563

Kumar SS, Priyanshu V (2015) Advanced hydrogen production through methane cracking: a review. Sci Technol 1(3):109-123

Lapeña-Rey N, Mosquera J, Bataller E, Ortí F (2010) First fuel-cell manned aircraft. J Aircr 47:1825-1835

Lattin WC, Utgikar VP (2007) Transition to hydrogen economy in the United States: a 2006 status report. Int J Hydrog Energy 32:3230-3237

Lefebvre TH, Corbett RA, Gurbin GM, MacBain AA, McCauley GF, Portelance A, Rose MW (1981) Energy alternatives. Report of the special committee on alternative energy and oil substitution to the parliament of Canada. Supply and Services, Ottawa, Canada

Lewis MA, Masin JG (2009) Evaluation of alternative thermochemical cycles: part II: the down-selection process. Int J Hydrog Energy 34:4125-4135

Lewis MA, Masin JG, O'Hare PA (2009) Evaluation of alternative thermochemical cycles: part I: the methodology. Int J Hydrog Energy 34:4115-4124

Lomonaco G, Marotta R (2014) Nuclear systems for hydrogen production: state of art and perspectives in transport sector. Glob J Energy Technol Res Updates 1:4-18

Lubis LI, Dincer I, Naterer GF, Rosen MA (2009) Utilizing hydrogen energy to reduce greenhouse gas emissions in Canada's residential sector. Int J Hydrog Energy 34:1631-1637

Maack MK, Skulason JB (2005) Implementing the hydrogen economy. J Clean Prod 14:52-64

Magnuson A, Anderlund M, Johansson O et al (2009) Biomimetic and microbial approaches to solar fuel generation. Acc Chem Res 42(12):1899-1909

Marban G, Valdes-Solis T (2007) Towards the hydrogen economy? Int J Hydrog Energy 32:1625-1637

Marchetti C (1973) Hydrogen and energy. Chem Econ Eng Rev $5: 7-15$

Marchetti C (1985) When will hydrogen come? Int J Hydrog Energy 10:215-219

Marchetti C (2006) Long-term global vision of nuclear-produced hydrogen. Int J Nucl Hydrog Product Appl 1(1):13-19

Maroufmashat A, Fowler M, Khavas S, Elkamel A, Roshandel R, Hajimiragha A (2015) Mixed integer linear programing based approach for optimal planning and operation of a smart urban energy network to support the hydrogen economy. Int J Hydrog Energy (in press)

Midilli A, Ay M, Dincer I, Rosen MA (2005a) On hydrogen and hydrogen energy strategies-I: current status and needs. Renew Sustain Energy Rev 9:291-307

Midilli A, Ay M, Dincer I, Rosen MA (2005b) On hydrogen and hydrogen energy strategies-II: future projections affecting global stability and unrest. Renew Sustain Energy Rev 9:309-323
Mitchell J (1983) Status of hydrogen development for aircraft in five countries: a Canadian perspective. Int $\mathrm{J}$ Hydrog Energy 8: 453-458

Mourato S, Saynor B, Hart D (2004) Greening London's black cabs: a study of driver's preferences for fuel cell taxis. Energy Policy 32:685-695

Muradov NZ, Veziroglu TN (2008) "Green" path from fossil-based to hydrogen economy: an overview of carbon-neutral technologies. Int J Hydrog Energy 33:6804-6839

Naterer GF, Suppiah S, Lewis M, Gabriel K, Dincer I, Rosen MA, Fowler M, Rizvi G, Easton EB, Ikeda BM, Kaye MH, Lu L, Pioro I, Spekkens P, Tremaine P, Mostaghimi J, Avsec A, Jiang J (2009) Recent Canadian advances in nuclear-based hydrogen production and the thermochemical $\mathrm{Cu}-\mathrm{Cl}$ cycle. Int $\mathrm{J}$ Hydrog Energy 34:2901-2917

Naterer G, Suppiah S, Stolberg L, Lewis M, Wang Z, Daggupati V, Gabriel K, Dincer I, Rosen MA, Spekkens P, Lvov SN, Fowler M, Tremaine P, Mostaghimi J, Easton EB, Trevani L, Rizvi G, Ikeda BM, Kaye MH, Lu L, Pioro I, Smith WR, Secnik E, Jiang J, Avsec J (2010) Canada's program on nuclear hydrogen production and the thermochemical $\mathrm{Cu}-\mathrm{Cl}$ cycle. Int $\mathrm{J}$ Hydrog Energy 35:10905-10926

National Academies of Engineering (2004) The hydrogen economy: opportunities, costs, barriers, and R\&D needs. Report, Washington, DC

Nel WP, Cooper CJ (2009) Implications of fossil fuel constraints on economic growth and global warming. Energy Policy 37: $166-180$

Nersesian RL (2010) Energy for the 21st century: a comprehensive guide to conventional and alternative sources, 2nd edn. M. E. Sharpe, Armonk

Niaz S, Manzoor T, Pandith AH (2015) Hydrogen storage: materials, methods and perspectives. Renew Sustain Energy Rev 50: $457-469$

Ongena J, Van Oost G (2006) Energy for future centuries: prospects for fusion power as a future energy source. Trans Fusion Sci Technol 49:3-15

Onuki K, Inagaki Y, Hino R, Tachibana Y (2005) Research and development on nuclear hydrogen production using HTGR at JAERI. Prog Nucl Energy 47:496-503

Orhan MF, Babu BS (2015) Investigation of an integrated hydrogen production system based on nuclear and renewable energy sources: comparative evaluation of hydrogen production options with a regenerative fuel cell system. Energy 88:801-820

Parthasarathy P, Narayanan KS (2014) Hydrogen production from steam gasification of biomass: influence of process parameters on hydrogen yield-a review. Renew Energy 66:570-579

Penner SS (2006) Steps toward the hydrogen economy. Energy $31: 33-43$

Ponomarev-Stepnoi NN (2004) Nuclear-hydrogen power. At Energy 96:375-385

Preethi V, Kanmani S (2013) Photocatalytic hydrogen production. Mater Sci Semicond Process 16:561-575

Rosen MA (2009) Towards energy sustainability: a quest of global proportions. Forum Public Policy Online: J Oxf Round Table, Summer 2008 edn, pp 1-20

Rosen MA (2010) Advances in hydrogen production by thermochemical water decomposition: a review. Energy 35:1068-1076

Rosen MA, Scott DS (1998) Comparative efficiency assessment for a range of hydrogen production processes. Int $\mathrm{J}$ Hydrog Energy 23:653-659

Rosen MA, Dincer I, Kanoglu M (2008) Role of exergy in increasing efficiency and sustainability and reducing environmental impact. Energy Policy 36:128-137 
Rydén M, Lyngfelt A (2006) Using steam reforming to produce hydrogen with carbon dioxide capture by chemical-looping combustion. Int J Hydrog Energy 31:1271-1283

Santarelli M, Cali M, Macagno S (2004) Design and analysis of standalone hydrogen energy systems with different renewable sources. Int J Hydrog Energy 29:1571-1586

Schultz K, Herring S, Lewis M, Summers W (2005) The hydrogen reaction. Nucl Eng Int 50:10-19

Scott DS (1987) Hydrogen: national mission for Canada. Report of the Advisory Group on hydrogen opportunities. Minster of Supply and Services, Ottawa, Canada

Scott DS (2007) Smelling land: the hydrogen defense against climate catastrophe. Canadian Hydrogen Association, Ottawa

Sharma S, Ghoshal SK (2015) Hydrogen the future transportation fuel: from production to applications. Renew Sustain Energy Rev 43:1151-1158

Shoko E, McLellan B, Costa D (2006) Hydrogen from coal: production and utilisation technologies. Int $\mathrm{J}$ Coal Geol 65:213-222

Sigfusson TI (2007) Pathways to hydrogen as an energy carrier. Philos Trans R Soc Lond A 365(1853):1025-1042

Silverstein HB (1982) Canada and hydrogen systems: an energy policy for a nation. Int J Hydrog Energy 7:615-621

Slotin LA (1983) The hydrogen economy: future policy implications. Int J Hydrog Energy 8:291-294

Smith WN, Santangelo JG (Eds) (1980) Hydrogen production and marketing. ACS symposium series 116. American Chemical Society, Washington, D.C

Srinivasan N, Shiga Y, Atarashi D, Sakai E, Miyauchi M (2015) A PEDOT-coated quantum dot as efficient visible light harvester for photocatalytic hydrogen production. Appl Catal B: Environ 179:113-121

Steinfeld A (2005) Solar thermochemical production of hydrogen: a review. Sol Energy 78:603-615

Tanksale A, Beltramini JN, Lu GM (2010) A review of catalytic hydrogen production processes from biomass. Renew Sustain Energy Rev 14:166-182

Thomas CE (2009) Fuel cell and battery electric vehicles compared. Int J Hydrog Energy 34:6005-6020

Torjman M, Shaaban H (1998) Nuclear energy as a primary source for a clean hydrogen energy system. Energy Convers Manag 39:27-32

Turgut ET, Rosen MA (2010) Partial substitution of hydrogen for conventional fuel in an aircraft by utilizing unused cargo compartment space. Int J Hydrog Energy 35:1463-1473
Turner J, Sverdrup G, Mann MK, Maness P-C, Kroposki B, Ghirardi M, Evans RJ, Blake D (2008) Renewable hydrogen production. Int J Energy Res 32:379-407

Turpeinen E, Raudaskoski R, Pongracz E, Keiski RL (2008) Thermodynamic analysis of conversion of alternative hydrocarbon-based feedstocks to hydrogen. Int J Hydrog Energy 33:6635-6643

Ursua A, Gandia LM, Sanchis P (2012) Hydrogen production from water electrolysis: current status and future trends. Proc IEEE 100(2):410-426

Utgikar V, Ward B (2006) Life cycle assessment of ISPRA Mark 9 thermochemical cycle for nuclear hydrogen production. J Chem Technol Biotechnol 81:1753-1759

Vasyanina TV, Alekseev IA, Bondarenko SD, Fedorchenko OA, Konoplev KA, Arkhipov EA, Uborsky VV (2008) Heavy water purification from tritium by CECE process. Fusion Eng Des 83:1451-1454

Verfondern K, Nishihara T (2005) Safety aspects of the combined HTTR/steam reforming complex for nuclear hydrogen production. Prog Nucl Energy 47:527-534

Verhelst S (2014) Recent progress in the use of hydrogen as a fuel for internal combustion engines. Int J Hydrog Energy 39:1071-1085

Veziroglu A, Macario R (2011) Fuel cell vehicles: state of the art with economic and environmental concerns. Int $\mathrm{J}$ Hydrog Energy 36:25-43

Veziroglu TN, Sahin S (2008) 21st century’s energy. Energy Convers Manag 49:1820-1831

Wallace JS, Ward CA (1983) Hydrogen as a fuel. Int J Hydrog Energy $8: 255-268$

Winter CJ (2009) Hydrogen energy—abundant, efficient, clean: a debate over the energy-system-of-change. Int J Hydrog Energy, Supplement 1, 34(14):S1-S52

Yang J, Sudik A, Wolverton C, Siegel DJ (2010) High capacity hydrogen storage materials: attributes for automotive applications and techniques for materials discovery. Chem Soc Rev 39:656-675

Yildiz B, Kazimi MS (2006) Efficiency of hydrogen production systems using alternative energy technologies. Int J Hydrog Energy 31:77-92

Zeradjanin AR, Topalov AA, Cherevko S, Keeley GP (2014) Sustainable generation of hydrogen using chemicals with regional oversupply-feasibility of the electrolysis in acidoalkaline reactor. Int J Hydrog Energy 39:16275-16281 